The objective of this study was to compare iron levels of infants fed with supplementary foods because of malnutrition,to those who were supported with complementary foods from sixth months of age, when the breast milk alone is not sufficient. Eighty-four healthy infants aged 6 to 9 months were enrolled. Infants without a nutritional problem, with sufficient iron stores, weighing over 10th percentile were enrolled in the control group, while babies weighting over 3 rd percentile, who were not breastfed and did not take a balanced and sufficient diet, without a chronic diseases and who were not born preterm were enrolled in the study group. All of the infants were followed for 3 months. Physical examination findings and complete blood count, iron, iron binding, ferritin, zinc test results were recorded monthly. Infants with malnutrition who could not take breast milk were supported with a follow-up formula (Bebelac). Mean ages were $7.2 \pm 1.28$ and $7.3 \pm 1.1$ months in the study and control groups respectively. Statistically significant increase was demonstrated in the MCV and iron levels of the infants supplemented with follow-up formula. MCV decreased significantly in the control group. Mean ferritin values increased from $53.2 \pm$ $41.8 \mathrm{mg} / \mathrm{L}$ to $64.7 \pm 89.7 \mathrm{mg} / \mathrm{L}$ in the study group, while decreased from $42.8 \pm 34.0 \mathrm{mg} / \mathrm{L}$ to $34.6 \pm 29.3 \mathrm{mg} / \mathrm{L}$ in the control group. In the study group, significantly higher levels of ferritin were measured in the last assessment, compared to the control group. In conclusion, increase in the iron stores of follow-up formula fed infants was observed during the follow-up period.

\section{PO-0164 PAEDIATRIC SOFT TISSUE SARCOMA: A TEN YEAR REVIEW}

M Pinheiro, A Maia Ferreira, A Pinto. Pediatrics, Instituto Português de Oncologia, Porto, Portugal

10.1136/archdischild-2014-307384.826

Background and aims Paediatric soft tissue sarcomas are rare tumours that account for about $7 \%$ of all childhood cancers. $50-60 \%$ of these are rhabdomyosarcoma (RMS), while the remainder are non rhabdomyosarcoma soft tissue sarcomas (NRSTS). To evaluate the clinical characteristics, treatment modalities and outcome of paediatric soft tissue sarcomas.

Methods A retrospective analysis of data from 51 patients diagnosed and treated from 2003 to 2013.

Results 51 patients, 30 male and 21 female, median age of 10 years old at diagnosis. $92 \%$ showed a mass at diagnosis. The most common site of disease was the extremities (20 cases). Histology: 51\% RMS (embryonal: 12 patients; alveolar: 12 patients; other: 2 patients) and 49\% NRSTS (PNET 5 patients; malignant peripheral nerve sheath tumour: 3 patients; other: 17 patients). IRS group: $29 \%$ group I, $14 \%$ group II, $28 \%$ group III and 29\% group IV. Most patients received multimodality therapy (radiotherapy, chemotherapy and surgery). 31\% (16 patients) died due to disease progression: 7 alveolar RMS, $11 \geq 10$ years old and 13 group III-IV. Time from diagnosis to death was between 7 months and 5 years. Of the 34 living patients, 74\% were in first complete remission. The median follow-up time was 38 months.

Conclusions Alveolar RMS is more common in the extremities and the embryonal in the genitourinary tract. NRSTS are more common in children $\geq 10$ years. The absence of metastases and the tumour size $\leq 5 \mathrm{~cm}$ were associated with a better prognosis $(\mathrm{p}<0.05)$.

\section{PO-0165 PREDICTORS OF CHRONIC PRIMARY IMMUNE THROMBOCYTOPENIA}

${ }^{1} \mathrm{~L}$ Sfaihi, ${ }^{1} \mathrm{Y}$ Belfitouri, ${ }^{2} \mathrm{O}$ Kassar, ${ }^{1} \mathrm{I}$ Maaloul, ${ }^{1} \mathrm{TH}$ Kamoun, ${ }^{2} \mathrm{M}$ Elloumi, ${ }^{1} \mathrm{M}$ Hachicha. ${ }^{1}$ Pediatrics, Hédi Chaker University Hospital, Sfax, Tunisia; ${ }^{2}$ Hematology, Hédi Chaker University Hospital, Sfax, Tunisia

\subsection{6/archdischild-2014-307384.828}

Background and aims The primary immune thrombocytopenia (ITP) in children has a favourable evolution in most of cases. Chronic ITP has been noted in $14-30 \%$ of the cases. This study reviewed the pattern of presentation and response to therapy in patients with ITP, in order to identify risk factors for chronic disease.

Methods We conducted a retrospective study of all cases of ITP in paediatrics and haematological departments of Hedi Chaker University Hospital in Sfax, during a period of 15 years (1995 to 2009). Predictors of chronicity were investigated using Fisher's test with a significance if $\mathrm{p}<0.05$.

Results 140 cases of ITP were collected including 75 girls (54\%) and 65 boys $(46 \%)$. The average age was 6 years 7 months (3 months to 15 years). The diffuse mucocutaneous purpura was constant and mucosal haemorrhages were present in one third of cases. The mean platelet count was $25000 / \mathrm{mm}^{3}\left(1000 / \mathrm{mm}^{3}\right.$ to $\left.50000 / \mathrm{mm}^{3}\right)$. Therapeutic abstention was the rule in 19 cases (14\%), 111 children received corticosteroids (79\%) and 10 children received immunoglobulins associated with corticosteroids (7\%). Fifteen patients were lost of follow up and evolution has identified two groups: acute ITP in 95 cases (67\%), and chronic ITP in 30 cases $(21 \%)$. The parameters that were found as predictors of chronicity were female sex and age.

Conclusions Acute ITP is the most common. Chronic forms are found in one fifth of cases. The determination of risk factors for chronicity can make an early prognosis.

\section{PO-0166 THE LANGERHANS CELL HISTIOCYTOSIS IN CHILDREN: STUDY OF 11 CASES}

L Sfaihi, Y Belfitouri, F Kamoun, I Maaloul, S Alibi, T Kamoun, M Hachicha. Pediatrics, Hédi Chaker University Hospital, Sfax, Tunisia

\subsection{6/archdischild-2014-307384.829}

Background and aims Langerhans cell histiocytosis (LCH) is a rare disease of unknown cause with manifestations ranging from isolated granulomatous lesions to life-threatening multi-system organ involvement.

In this study we aimed to evaluate the characteristics, diagnosis, treatment modalities and prognosis of $\mathrm{LCH}$.

Methods We conducted a retrospective study of all cases of LCH in paediatrics department of Hedi Chaker University Hospital in Sfax during a period of 16 years (1997-2013) Epidemiologic, clinical, radiological, diagnostic and therapeutic variables were collected.

Results We collected 11 cases of LCH. The average age at diagnosis was 3 years 4 months. The patients' presenting symptoms were: exophtalmia (3 cases), polyuropolydispsic syndrome (3 cases), prolonged fever (2 cases), lymphadenopathy (5 cases). Laboratory tests showed diabetes insipidus (3 cases) and bicytopenia ( 1 case). The diagnosis was confirmed by histopathologic examination in all cases.

Bone was the most frequently affected organ (9 cases) followed by skin (19.2\%). Initially, 4 patients had single-system involvement (SS), 3 with mulisystem (MS) disease without risk 